\title{
The Integrated Structural and Measurement Models of Existential Annihilation Anxieties (EAA) and Their Potential Contribution to Clinical Science: Two Studies on Western and Non-Western Samples
}

\author{
Ibrahim Kira ${ }^{1,2 *}$, Hanaa Shuwiekh ${ }^{3}$, Justyna Kucharska ${ }^{4}$, Amthal Al-Huwailah ${ }^{5}$ \\ ${ }^{1}$ Center for Cumulative Trauma Studies, Stone Mountain, GA, USA \\ ${ }^{2}$ Center for Stress, Trauma and Resiliency, Georgia State University, Atlanta, GA, USA \\ ${ }^{3}$ Fayoum University, Fayoum, Egypt \\ ${ }^{4}$ University of Westminster, London, UK \\ ${ }^{5}$ College of Social Sciences, Kuwait University, Kuwait City, Kuwait \\ Email: *kiraaref@aol.com
}

\begin{abstract}
How to cite this paper: Kira, I., Shuwiekh, H., Kucharska, J., \& Al-Huwailah, A. (2019). The Integrated Structural and Measurement Models of Existential Annihilation Anxieties (EAA) and Their Potential Contribution to Clinical Science: Two Studies on Western and Non-Western Samples. Psychology, 10, 449-480.
\end{abstract} https://doi.org/10.4236/psych.2019.104031

Received: January 30, 2019

Accepted: March 5, 2019

Published: March 8, 2019

Copyright () 2019 by author(s) and Scientific Research Publishing Inc. This work is licensed under the Creative Commons Attribution International License (CC BY 4.0).

http://creativecommons.org/licenses/by/4.0/

\section{c) (i) Open Access}

\begin{abstract}
Current study integrated the existential annihilation anxieties (EAA) models and identified four EAA types: psychic, collective, status, and physical. Based on this conceptual framework, the authors developed a scale to measure the four types and assessed the scale's construct and predictive validity, reliability and stability in two Western (UK, $\mathrm{N}=178$ ) and non-Western (Egypt, $\mathrm{N}=$ 490) samples. The study measured trauma types, PTSD, psychopathology, depression, self-esteem, will to exist and other related variables. Exploratory and confirmatory factor analysis confirmed the four-factor structure of the construct that was strictly invariant across groups in both samples. EAA and its four subscales were highly correlated with psychopathology, depression, and PTSD, and negatively correlated with "will to exist" and self-esteem in both samples. Path analysis and PROCESS macro indicated that EAA had strong direct effects, and mediated the effects of cumulative trauma on psychopathology. While personal identity trauma predicted psychic EAA, collective identity traumas predicted collective EAA, and status identity trauma predicted status EAA, survival trauma did not predict physical death EAA in either sample. Curve estimation clarified the non-linear dynamics involved in EAA's types' intersections and the discrepancy in physical EAA results. We discussed the inclusion of EAA in clinical practice and in the future development of intervention and prevention strategies.
\end{abstract}




\section{Keywords}

Existential Annihilation Anxiety, Personal Identity Trauma, Status Identity Trauma, Collective Identity Trauma, Will to Exist, Live and Survive, Psychopathology, PTSD, Self-Esteem

\section{Introduction}

Existential anxiety and existential annihilation anxieties are ignored in clinical science, though they have crucial role in mental health. The threats to the existence and existential anxieties erupted due to these threats are the most serious specific threats that the person may encounter.

Several unique but overlapping conceptual frameworks on existential anxieties emerged in the literature. One framework focused on the personal existential anxieties (anxieties caused by events that threatened the existence of the person's identity) (e.g., Berman, Weems, \& Stickle, 2006; Shaver, \& Mikulincer, 2012; Weems, Costa, Dehon, \& Berman, 2004). Another framework focused on annihilation anxieties (AA) (fear of being overwhelmed, merged, penetrated, fragmented, and destroyed, that is triggered by survival threats) (e.g., Hurvich, 2004, Allen, Hurvich, \& Mcguire, 2017). A third framework focused on death anxiety (anxiety caused by the anticipation of death) (e.g., Iverach, Menzies, \& Menzies, 2014) and mortality salience (the inevitability of dying) (e.g., Burke, Martens, \& Faucher, 2010).

Current conceptual models on existential anxieties, and related measurement strategies have individualistic bias and are focused either on anxieties related to fear of physical identity elimination (fear of death) (e.g., van Bruggen et al., 2017), or on personal or psychic identity (e.g., Hurvich, 2004), ignoring at least two other crucial types of existential threats: existential threats to collective identities (e.g., discrimination, and genocide), and existential threat to status identity (e.g., poverty, servitude, and cast systems). The individual existence is impeded in and a part of a broader hierarchical network of groups and systems that the individual cannot possibly live or exist without (e.g., Lambert et al., 2013).

We propose that what makes an event distressing and traumatic which is one of the focuses of clinical science, is its perceived threat to the existence, maintenance, and development of one of the person's four salient identities. The actual or perceived existential threat of an event will trigger the different adaptive and non-adaptive responses. Additionally, the existential threats to different personal, status, physical and collective identities the person possesses can intersect and create vicious amplification loops, as all these threats are targeting different aspects of the same person.

Additionally, the mechanisms underlying the threat trajectory that produces anxiety specifies unique emotional, cognitive, and neurobiological pathways linking different threats to multiple forms of psychopathology including interna- 
lizing, externalizing and thought disorders (e.g., McLaughlin \& Lambert, 2017). Different threats alter the development of cortical and subcortical circuits involved in fear learning, emotion regulation and salience processing (e.g., LeDoux \& Pine, 2016). However, most theories of cumulative threats (and cumulative risks and traumas) (e.g., Evans, Li, \& Whipple, 2013) lack specificity about the target of threats/ risks (threats or risks to what). Further, because of the lack of specificity, they offer little insight into the mechanisms that explain the links between exposure and outcomes. We propose that existential threats to different identities produce specific existential anxieties that intersect and accumulate to generate different types of psychopathology. Unfortunately, existential anxieties and their measurement are mostly unrecognized or given inadequate attention in clinical science.

\subsection{The Clinical Importance of Perceived Existential Threats and Existential Anxieties}

The focus of clinical psychology and its allied disciplines that treated anxiety is on general anxiety, while specific anxieties related to threats to the existence of one or more of the person's multiple identities are mostly underestimated. While existential threats are potentially the most distressing their contribution to the health and mental health are understudied as they are almost absent, or rarely addressed in current clinical literature and interventions especially with multiply traumatized. Several early scholars have emphasized the psychotherapeutic benefit of addressing existential issues (Frankl, 1963; Spinelli, 2005; Yalom, 1980). In the absence of convincing conceptual framework about identity stressors and traumas, it was challenging to provide and identify the existential dynamics of identity traumas and provide measurement strategy that affords convincing evidence of their importance in clinical science. Current interventions that do not address the roots and outcomes of cumulative and existential dynamics offer disappointing results. For example, Steenkamp, Litz, Hoge, \& Marmar (2015), reviewing the randomized clinical trials, noticed that about $2 / 3$ rds of military veterans treated with prolonged exposure or cognitive behavior therapy, the most researched evidence-based treatments, continue to meet criteria for PTSD after treatment. The outcomes of such evidence-based intervention, while statistically significant, it is clinically inadequate. Research indicates that dropout and nonresponse rates are high and that residual symptoms remain following these treatments (Bradley, Greene, Russ, Dutra, \& Westen, 2005; Larsen, Fleming, \& Resick, 2018; Schottenbauer, Glass, Arnkoff, Tendick, \& Gray, 2008). There is a need to explore new avenues to understanding and help trauma victims beyond the current inadequate focus on a single trauma and expand our clinical reach to the cumulative and existential dynamics, with hope to improve clinical outcomes.

One potential reason for ignoring the role of existential anxieties in clinical science is that the concept was initially grown within the confines of existential philosophy (e.g., Heidegger, 1927/1979; Kierkegaard, 1843/1954a; Sarter, 1956; 
Sartre, 1992), and there is no integrated conceptual or empirical framework that delineates a measurable structure or explores its dynamics in the etiology of health and illness. The fragmented existing frameworks need to be integrated as part of a proposed identity framework. Different intersected identity related to Existential Annihilation Anxieties (EAA) can be a unifying and integrative concept that is measurable and testable. Such EAAs includes anxieties that may erupt upon exposure to different existential threats to personal, role, physical and social identities.

\subsection{The Continuum of Existential Concerns and Existential Annihilation Anxiety}

Existential concerns, the concerns about the present and the future existence of one of the person's salient identities and its related value systems and assets, can range in their intensities from simple indirect concerns/threats to serious concerns and direct threats of the elimination and annihilation of the targeted identity. In normal circumstances, most people have existential concerns, about themselves, their independence and autonomy, their social and economic status, their significant others, and their groups. Such concerns may fluctuate with ebbs and flows of relevant stressors that are mostly manageable. However, upon exposure to perceived significant and relevant identity threats, existential anxiety and fear of identity elimination rise and the individual are thrown into existential vulnerability (Fuchs, 2013) and into different types of existential annihilation anxiety (Kira et al., 2012b, Kira, Templin, Lewandowsky, \& Shuwiekh, 2018). In such situations, the nature and substance of existence and the human condition as temporary, time-limited and finite, e.g., the fragility and dependence, the inevitability of inequitable hierarchical status, mortality salience and finiteness of life, and the salience of group extinction, may erupt. While there are different mechanisms such as "will-to exist-live and survive", self-esteem and self-efficacy that buffer against EAA, these buffers can break in a non-linear threshold eruption. These fundamental conditions may give rise to psychopathology (e.g., Fuchs, 2013; Kira et al., 2012b, 2013a). The threats of existential annihilation, as in the cases of terminal illness, servitude, cast systems, extreme poverty, and genocide are the most existential threats, which deserve more focused attention in clinical science for their adverse effects on the person and his/her network and cross-generationally.

Further, different types of EAA may intersect amplifying their total impact. Models that use principles of nonlinear dynamics can help illuminate the flux and patterning of such intersection. We propose, that the relationship between EAA types, especially in the case of intersection, and other trauma variables are complex and mostly non-linear.

\subsection{Identity Traumas and the Structure of EAA}

According to the developmentally-based trauma framework (DBTF) (Kira, 2001; Kira, Ashby, Lewandowski et al., 2013; Kira et al., 2010; Kira, Ashby, Lewan- 
dowski, Smith, \& Odenat, 2012; Kira et al., 2015; Kira, Lewandowski, Chiodo, \& Ibrahim, 2014; Kira, 2019; Kira et al., 2018), and collective terror management theory (CTMT) (Kira, 2002), identity development in adolescents and early adulthood marks the emergence of agency and interdependence leading to establishing a hierarchy of different intersecting and interacting identities. Some of these identities are more salient or more dormant according to the triggering events and situations. The dynamic hierarchy includes four main identity types: personal, collective or social, role or status, and physical identities. Concerns about the existence, maintenance and continuous emergence of one or more of the individual's identities can escalate upon exposure to relevant and important threats, stressors, and traumas. According to the DBTF and CTM frameworks, there are four primary sources of EAA: the threats to personal identity's psychic annihilation as an autonomous independent actor, the threats to collective and social identities' collective annihilation (Kira, Shuwiekh et al., 2018). Another source of such socially-made dimension is the extreme threats by social structure traumas (social-structural violence) and other systemic threats to the status of the person. We acquire our perceived status through upward and downward social comparisons (Festinger, 1954), or through a pre-imposed social hierarchy, for example, the cast and slavery systems. The relative standing and comparative status of inferiority/superiority determine access to education, wages, admiration, and even the affection of others. Implicated in the comparative status model is the negative or positive self-evaluation. Social comparisons may constitute a threat to the self and generate negative (deflated) self-evaluation in lower status members, and positive (or inflated) self-evaluation in higher status members (e.g., Wood, 1989). Adler's (1927) social psychological theory of personality viewed that striving for superiority is the central human motivation and that feelings of inferiority are at the root of neurotic dysfunction. Examples of such status identity traumas are extreme inequalities, poverty and cast systems that threaten the individual's social status and self-evaluations. Other examples include school dropout, failed business or firing that threaten the statuses of the individual. For example, the loss of self-perceived social status but not the loss of income or social support explained significant variance in the adverse health effects of unemployment (Krug \& Eberl, 2018).

Another well-studied identity threat is a death threat to the physical identity of the individual. Threats to physical identity and mortality salience are the main focus of current psychiatric, trauma, and terror management theories (e.g., Pyszczynski, Greenberg, \& Solomon, 1999). Fear of personal identity psychic annihilation is the focus of annihilation anxiety theory in psychoanalytic literature. However, fear and anxieties about the collective annihilation of one or more of the person's social identities, and the perceived extinction salience is almost a missing variable in mainstream psychology. As emphasized, the current mainstream psychology, has an individualistic bias (e.g., Christopher \& Hickinbottom, 2008), ignoring an essential part of the personal existence, which make it deficient and unable to predict or develop strategies to prevent group-based 
violence or to develop effective interventions for victims of EAA. Political psychology started to recognize the importance of the concept of collective annihilation anxieties in the Holocaust and genocides studies (e.g., Hirschberger, Ein-Dor, Leidner, \& Saguy, 2016; Kira, Alawneh, Aboumediene, Lewandowski, \& Laddis, 2014; Kira, Shuwiekh, Rice, Al Ibraheem, \& Aljakoub, 2017; Shrira, 2015; Yair, 2014; Wohl, Branscombe, \& Reysen, 2010).

\section{Measuring EAA}

They are many measures of existential anxiety (EA) with most of them focused on measuring fear of death (e.g. van Bruggen, Vos, Westerhof, Bohlmeijer, \& Glas, 2015). Closely related is Hurvich Experience Inventory (HEI), with its different versions (Allen, Hurvich, \& Mcguire, 2017) which try to measure the psychoanalytic concept of psychic annihilation anxiety, traditionally measured by projective tests (Hurvich, Benveniste, Howard, \& Coonerty, 1993). A new attempt to introduce and measure EAA, from an integrative theoretical framework that includes especially group-based existential AA and social status related EAA, in addition to the psychic annihilation fears is proposed by (Kira et al., 2012b, 2013b). The previously developed three-item short measure of EAA short form, in a sample of adolescents and adults $(\mathrm{N}=2743)$, showed to have excellent psychometric properties with high $\alpha$ reliability, test-retest stability, discriminant, and predictive validity, as well as strong measurement and structural invariance across gender, age, and cultural groups. In this study, EAA fully mediated the effects of cumulative stress and trauma on PTSD (Kira, Templin et al., 2012b; Kira, Templin, Lewandowsky, \& Shuwiekh, 2018). In the present paper, we further develop the short measure to include all the four types of EAA with separate subscale for each.

\subsection{Conceptual Structural Model of the Dynamics of EAA}

The individual does not exist alone, and his/her existence is embedded in a broader network of social groups and systems. Events that may threaten one or more of the person's identities (i.e., identity stressors and traumas), can trigger the existential anxieties that range in intensity from existential concerns to existential annihilation anxieties (EAA). EAA mediate the effects of such stressors and traumas on psychopathology and PTSD. Personal identity traumas trigger psychic EAA; collective identity traumas trigger collective EAA; status identity traumas trigger status identity EAA. All types of EAAs intersect and amplify each other to exact and to mediate a large size of the effects of cumulative identity traumas on PTSD and psychopathology in general.

Further, we propose that "will to exist, live, survive and thrive," is at the core of person's existential identities and contribute to buffering against their negative impact. Additionally, self-evaluation (e.g., self-esteem) is another mechanism that may alleviate EAA. Will to exist, and self-evaluation can function as part of the dynamic resiliency buffer against the negative impact of different 
types of EAA.

The goal of current work is to translate the discussed integrated conceptual framework of EAA and its dynamics in a measurement model and test it and explore EAA mental health impact. In this study, building on the previous work and the developed conceptual model, we will construct and test a scale that measures the four proposed components of EAA. We will test the developed measure and the proposed conceptual model of EAA dynamics in different samples to explore its invariance across Western and non-Western cultures. The objective is to empirically test the measure and related conceptual model's validity and potential utility in clinical science.

\subsection{Hypotheses}

Hypothesis 1: The constructed EAA measure and its subscales have good structural, convergent, divergent and predictive validities, as well as adequate internal consistency, and stability over time in both Western and non-western samples. It highly associates with psychopathology, depression, suicidality, cumulative and different identity trauma types, gender discrimination (and other discriminations), poor physical health, and PTSD. The measure is identity-based as it associates positively with identity salience and entrapment. It is significantly and negatively associated with the will to exist and self-esteem.

Hypothesis 2: The measure is invariant across groups in both the Egyptian and UK samples and between genders in the Egyptian Sample.

Hypothesis 3: The measure and its four subscales have good predictive validity:

1) EAA significantly mediates the effects of cumulative life traumas, as well as directly impact psychopathology.

2) Each type of trauma predicts (triggers) the respective type of EAA, personal identity trauma predicts personal EAA, collective identity trauma predicts collective EAA, status/role identity trauma predicts status EAA, and physical identity trauma predicts death EAA.

Hypothesis 4: Will to exist, live, survive and thrive is a strong instinctual drive that helps the individual deal with EAA and is negatively associated with it. Further, positive self-evaluation (e.g., self-esteem) will associate negatively with EAA.

Hypothesis 5: The associations between EAA four types and other trauma variables are mostly non-linear.

\section{Methods}

\subsection{Constructing and Piloting the EAA Measure}

A focus/task group of five professionals in the field identified a pool of 100 items and chose 18-items that have high face validity and direct relevance to the defined four components of EAA. After the initial testing of the measure on a small sample of 10 people, based on their feedback, three items were deleted. The re- 
maining 15 items represent the new measure of EAA that includes four subscales: personal (psychic) EAA, collective EAA, status EAA, and physical EAA (See Appendix 1). Further, we conducted, on a separate sample of 34, a test-retest (4 weeks interval) of the EAA scale to test its stability. Further, authors developed a questionnaire that included the measure as well as measures of the different independent, mediator and outcome variables presented in the conceptual model, as will be detailed in the measures section.

\subsection{The First Sample (The Egypt Sample)}

\subsubsection{Procedures}

The questionnaire was administered to participants in person individually and in groups, from the first week of October through the first week of December of 2017 in Egypt. The research was conducted with the approval of a university institutional review board (IRB). The participation was voluntary. Each participant informed about the general goals of the study and signed informed consent to participate. Each participant took between 45 - 60 minutes to complete the questionnaire.

To obtain a diverse sample of participants, a purposive snowball sampling strategy was used. The current study was conducted in three Egyptian cities that may represent geographically and culturally the different mix in Egyptian society. Three research teams of graduate students in clinical psychology (a different team in each city) collected the data under the direct supervision of their advisors. We increased the recruitment of Christians to enable a comparison between Muslims and Christian in this predominantly Muslim country.

\subsubsection{Participants}

The sample included $\mathrm{N}=490$, with $41.4 \%$ females. We included different ages and localities to test the EAA across age and locality groups. Age ranged from 14 to 75 , with Age Mean $=26.03, \mathrm{SD}=10.90$, with $20.4 \%$ adolescents. Localities included Fayoum (Middle Egypt) $(\mathrm{N}=184)$, Qena (Upper Egypt) $(\mathrm{N}=210)$, and Giza/Cairo $(\mathrm{N}=96)$, (which is mostly a melting pot of diversities) cities. For religion, 49.6\% were Muslims, and 50.4\% were Christians. It included students (64.5\%), employees (12.9\%), workers (3.1\%), merchants $(2.4 \%)$, professionals (3.4\%), and others (13.6\%). It included $28.6 \%$ married, $68.8 \%$ singles, and $2.6 \%$ had other marital statuses. Among participants 3\% reported to be poor or very poor, $21.9 \%$ reported to have either high or very high SES, while $75.1 \%$ reported being in the middle. For education $6.1 \%$ reported to be illiterate, $3.6 \%$ either elementary or intermediate education, $27.3 \%$ high school, $51.8 \%$ were at college and university level, while $11 \%$ at the graduate level.

\subsubsection{Translation of the Measures to Arabic}

All measures, except EAA measure, were previously translated into Arabic language and utilized on several research projects in different Arabic populations. For each of the three new measures, translation and back translation was con- 
ducted by psychologists who are fluent in both languages. All measures were tested on a focus group of 10 graduate students who gave feedback on the final versions.

\section{Measures}

\subsection{Independent Variables Measures}

The will to Exist, Live and Survive (WTLES) measure (Kira, Shweikh \& Moustafa, paper submitted for publication): The measure has six items focused on the different aspects of will to exist, live, survive and thrive. It includes items such as "I am motivated by a drive to live"; "My will to exist and survive adversity is generally? Each item was scored on five points scale: 4 . Very strong. 3. Strong, 2, Neutral, 1. Drained/ depleted, 0 extremely depleted. I have no will to survive. Exploratory and confirmatory factor analyses found that the measure has a one-factor structure. The measure's one-factor structure was strictly invariant across gender, cultural and religious groups. Test-retest reliability coefficient (4 weeks interval) on a sample $(\mathrm{N}=34$ ) found to be 0.82 . It was found to have good convergent, divergent and predictive validity. WTELS predicted a decrease in mental health symptoms, existential anxiety and an increase in self-esteem, emotion regulation (reappraisal) and posttraumatic growth. The Cronbach's reliability of the scale obtained with the present sample was $(\alpha=0.82)$

Cumulative Trauma Scale (CTS-Short version) (Kira et al., 2008). The CTS-L is a 61-item scale. Its short version (CTS-S), which is 32-item scale was used to assess Cumulative stress and Trauma and different trauma types. Each item describes an extremely stressful event. Each participant was asked to report first if $s /$ he experienced the event, how many times s/he experienced the event, how old they were the first time the event occurred, and how much it affected him/her (positively or negatively on a scale from $0-3$ for each). An example of its questions is "I was led to sexual contact with someone older than me." The CTS (L and S versions) provides two CT dose measures (1) occurrence and (2) frequency), and two appraisal subscales (negative and positive appraisal). The CTS-L has been used previously with different clinical and community populations of adults and children (Kira, 2001; Kira et al., 2008). Adequate internal consistency reliability has been reported (range $0.70-0.89$ ) and good construct and predictive validity have also been reported for both (Kira et al., 2008). For this study, we focused solely on the cumulative occurrence of six of the trauma types, including attachment trauma, (e.g., parental abandonment); personal identity trauma, (e.g., sexual abuse, physical abuse, rape, robbed, or mugged), survival or physical identity trauma, (e.g., shot at or stabbed); role identity traumas, (e.g., failed schooling or business) secondary trauma in the community, (e.g., witnessing or hearing about others traumas), and gender discrimination. Collective identity traumas included questions, (e.g., "I have been put down or threatened because of my race, religion, culture, or national origin"). The occurrence measures of each trauma type have an adequate test-retest stability that 
ranged between 0.90 and 0.95 in a sample of 35 over five weeks. The Cronbach's a of the CTS occurrence was 0.84 in the present study.

\subsection{Mediating Variables Measures}

Existential Annihilation Anxieties measure (EAA) (Kira et al., 2012b; Kira, Templin, Lewandowski, \& Shuwiekh, 2018). Its original short-form three items version was found to have high reliability, stability, and predictive validity. It was further developed in a 15 items measure in the current study. The current version has four subscales: Psychic EAA related to personal identity trauma (psychic), EAA related to collective identity trauma, EAA related to Social status traumas, and EAA related to fear of physical death.

The Rosenberg self-esteem scale (RSES) is a 10-item scale that measures global self-esteem (Rosenberg, 1965). Each item rated on a 4-point Likert-type scale with a range from strongly agree to disagree strongly and scored from 0 to 3. The scale divided into five positively worded and five negatively worded statements. The RSES has been translated and adapted to various languages including Arabic. Rosenberg reported good psychometrics for the scale and its reliability ranging from 0.85 to 0.88 . In previous Arabic samples, alpha was 0.75 . Test-retest using an independent sample of 35 males with four weeks interval yielded excellent stability coefficient of 0.983 . Its alpha reliability was 0.744 in the current study.

\section{Identity Salience Scale (ISS)}

The ISS (Kira, Alawneh et al., 2011) is a 10-item scale that was developed across two studies with 880 Palestinian adolescents. Identity salience, or dormancy, refers to the status of one domain of identity in the nested hierarchy, whether it is central or peripheral. It includes questions such as "I feel personally threatened by hate crimes committed against myself or the members of my race, religion, culture or ethnic group or another group of my belonging." Another example is "Sometimes I wish to die or kill somebody or myself before my ethnic, or religion or nation or any other group of my belonging harmed, eliminated or subjugated." The response indicates how much the participant disagrees or agrees on a scale ranging from 1 (entirely disagree) to 7 (absolutely agree). Higher scores indicate higher collective identity salience; lower scores highlight more personal identity salience. Exploratory and confirmatory factor analysis found support for two subscales: identity commitment and identity militancy. Internal consistency reliability (alpha) for the measure was .80 for adolescents (and 0.81 in another adult Palestinian sample; $\mathrm{N}=132$ ), with alphas of 0.74 for the commitment and 0.75 for the militancy (ready to die for your group) subscales. Test-retest reliability after three weeks was 0.76 . The scale's alpha was 0.86 for the Egyptian sample, and 0.92 in the UK sample.

\subsection{Outcome or Dependent Variables Measures}

Clinician-administered PTSD Scale CAPS-2 PTSD Measure (CAPS-2) (18 
items). This scale was developed by Blake et al. (1995). It is widely used to assess PTSD symptoms (DSM IV version). It is a structured clinical interview that evaluates 17 symptoms rated on frequency and severity on a 5-point scale. CAPS demonstrated high reliability with a range of $0.92-0.99$ and showed good convergent and discriminant validity (Weathers, Keane, \& Davidson, 2001). In this study, we used the frequency subscale of CAPS-2 that is currently widely used in psychiatric literature and is highly correlated with the total scale. The scale in the current study has high reliability with an alpha of 0.97 .

Psychopathology Screening measure (Kira, Shuwiekh, \& Kucharska, 2017) Adapted GAIN Short Screener (GAIN-SS) (Dennis, Chan, \& Funk, 2006) is a screener, that quickly identifies clients (adults and adolescents) who are likely to have mental health disorders, issues with crime/violence, and issues with substance use. The participant is asked to indicate if the behavior (or feeling) happened in the past month (scored 4), or happened in the last 2 - 3 months (scored 3 ), or in the last 3 - 12 months (scored 2), or the last year or more (scored 1), or never happened (scored 0 ). The original measure includes three parts: Internalizing, Externalizing, and substance abuse sections. High scores indicate potentially higher symptoms in these areas. The measure was adapted to include a section for psychoticism and dissociation, adding items from psychoticism/dissociation subscale of cumulative trauma disorder scale (Kira et al., 2012a). Further, items were added to internalizing that are related to PTSD symptoms. The original version did not include different PTSD symptoms. The goal of its adaptation was to include the three primary components of psychopathology: Internalizing, Externalizing and thought disorder (psychoticism) (e.g., Caspi et al., 2014; Laceulle, Volleberge, \& Ormel, 2015). The current adapted measure includes 20 items. Exploratory and Confirmatory Factor Analysis of the adapted measure in different data in Egypt and Poland yielded three factors: Internalizing, Externalizing and psychoticism. Test-retest using an independent sample of 35 males with four weeks interval yielded excellent stability coefficients ( 0.970 for internalizing, 0.908 for externalizing, 0.915 for the combined externalizing and addiction subscale. In the current study, alpha reliability for internalizing was 0.84 , 0.88 for externalizing and addiction, and 0.93 for psychoticism. The total scale of psychopathology scale has an alpha of 0.89 in current data.

Depression Single item measure (Chochinov, Wilson, Enns, \& Lander, 1997): This single item measure for depression was found to correctly identify the eventual diagnostic outcome of every patient, outperforming the questionnaire and visual analog measures.

Physical Health Scale (13 items, modified; Kira, Clifford, Wiencek, \& AlHaidar, 2001). The measure developed and used in previous studies on Iraqi refugees and Palestinians. The high score on the measure found to be highly associated with PTSD, CTD (complex PTSD), and older age (Kira et al., 2006). It found, in different studies, to have adequate reliability that ranged between 70 and 85. It has good test-retest stability of 0.98 over four weeks. It includes four questions about self-rated health, the effect of current health conditions on the 
ability to work, social relations and memory, using a 5-point Likert-type scale. It also includes a checklist of specific acute and chronic physical health problems, based on the taxonomy of health problems of ICD-9-CM codes for selected general medical conditions such as neurological and blood pressure disorders and digestive system, musculoskeletal, and endocrine illnesses. The higher the score, the worse is the participant health condition. The scale alpha reliability is 0.69 in the Egyptian sample, and 0.77 in the UK sample.

\section{Demographic Variables}

In addition to the independent and outcome variables measure, demographic information was collected and included age, gender, marital status, education, religion, and income. Yearly income was converted to score from 1 - 5 to reflect the different levels of income in different countries.

\subsection{The Second Sample (the UK Sample)}

\subsubsection{Procedures}

Participants were recruited using two strategies. The first was using a crowdsourcing website "prolific.ac", where the participants received $£ 2$ for completing the survey. We specified in the settings that they have to be students, age range 18 - 40, and nationality, country of birth and current country of residence: UK. Further, the link to the online survey was sent to a student's university organization in London.

\subsubsection{Participants}

Participants $(\mathrm{N}=178)$, included $60.7 \%$ females. Age ranged between 18 and 40, $\mathrm{M}=25.89$, and $\mathrm{SD}=5.66$. Among them, $48.9 \%$ were college students, $39.3 \%$ were employees, $6.2 \%$ were professionals, and $5.6 \%$ were others. Among them, $14.6 \%$ were married, $74.2 \%$ were single, $1.7 \%$ was divorced, and $9.6 \%$ had other marital statuses. For socioeconomic status, $7.3 \%$ reported to have a high income, $70.2 \%$ reported to have enough income, $20.8 \%$ reported to be poor, and $1.7 \%$ reported to be very poor. For religion, participants included 24.2\% Christians, $0.6 \%$ Jewish, $4.5 \%$ other religions, while $70.8 \%$ with no religious affiliation. For education, $21.3 \%$ had a high school, $57.3 \%$ had an undergraduate degree, and $21.3 \%$ had a postgraduate degree.

\subsubsection{Measures}

In addition to the measures used in the first study, we added measures for entrapment and existential uncertainty to check their convergence with EAA.

The Short Defeat and Entrapment Scale (SDES) (Griffith et al., 2015) is an 8-items scale that measures defeat (conceptualized as a failed social struggle) and entrapment (conceptualized as a perceived inability to escape from aversive situations). Exploratory and confirmatory factor analyses demonstrated that defeat and entrapment were best defined by a single factor. The scale had high internal consistency ( $\alpha=0.88$ to 0.94 ), showed criterion validity with hopelessness $(r=$ 0.45 to 0.93 ) and incremental validity. Additionally, the scale had an excellent test-retest reliability using single measures absolute agreement intraclass correla- 
tion coefficients across 12 months ( $r=0.88$ to 0.92$)$ within four samples: people with posttraumatic stress disorder, people with psychosis, care home employees, and people from community settings. The scale demonstrated validity through discrimination between clinical and nonclinical groups of participants. The measure had $\alpha=0.94$, in the current study.

Flexibility in Existential Beliefs and Worldviews: Existential Quest Scale (existential uncertainty) (Van Pachterbeke, Keller, \& Saroglou, 2012). The 9-item scale measures the openness to questioning and changing one's own existential beliefs and worldviews or "existential quest. The measure showed incremental validity regarding the prediction of relevant cognitive biases and empathy. Example of its items is "My way of seeing the world is certainly going to change again." A Likert 5 points scale used to assess the agreement/disagreement of each statement. The scale assesses the need for cognition, more secular or exploratory views on religious issues, and a tendency to search for a sense of meaning in life. Sample items include "Being able to doubt about one's convictions and to reappraise them is a good quality" and "My attitude toward religion and faith is likely to change according to my life experiences." The measure had $\alpha=0.82$, in the current study.

\subsubsection{Statistical Analysis}

The data were analyzed utilizing IBM-SPSS 22, as well as Amos 22 software. We used Cohen (1992) criteria and recommendations, or advanced software to determine the sample size that achieves medium population effect size at power $=$ 0.80 for $\alpha=0.05$ for the number of variables. We calculated frequencies and basic descriptions. We conducted zero-order correlation between the primary variables. We explored the differences between gender, age, regional and religious groups in EAA using independent sample t-test and one way-ANOVA.

We split the Egyptian sample ( $\mathrm{N}=245$, for each) using SPSS commands (e.g., select a random sample of the cases). We conducted exploratory-on the first sub-sample-and confirmatory factor analysis (CFA) on the second sub-sample, as well as on the UK sample. Following Byrne's (2012) recommendations, the criteria for good model fit were a non-significant $\left(\chi^{2}\right),\left(\chi^{2} /\right.$ d.f. $\left.>2\right)$, comparative fit index (CFI) values $>0.90$, and root-mean-square error of approximation (RMSEA) values $<0.06$. We investigated the reliability of the scale with the Cronbach's alpha. To test its predictive validity, we conducted mediated path analyses to test the predictive validity and the proposed conceptual model. Following the criteria outlined by Baron and Kenny (1986), to test the models of the effects of cumulative trauma on psychopathology, and PTSD, mediated by EAA, and the effects of different trauma types mediated by different EAA types on mental health variables. We will report direct, indirect, and total effects of standardized regression coefficients. Following Byrne's (2012) recommendations, the path model was evaluated to ensure an acceptable fit to the sample data using the same criteria for evaluating the structure model. We used a bootstrapping procedure with 10,000 bootstrap samples to examine the significance of direct, in- 
direct (mediated effects), and total effects and 95\% bias-corrected confidence intervals $(95 \% \mathrm{CI})$ for each variable in the model. Bootstrapping is a robust method to generate a sampling distribution and test the significance of direct, indirect and total effects. To simplify the presentation, we trimmed the model by eliminating the non-significant paths.

While path analysis can analyze several independent and dependent variables at the same time and identifies the total indirect effects, it cannot identify the mediators or specifies the effect of each. For this reason, we supplemented path analysis by SPSS PROCESS macro (Hayes, 2013). PROCESS, while analyzing only one independent and one dependent variable at a time, is able to analyze and identify mediators. We used PROCESS macro: model 4 , to test the direct effects and indirect effects through multiple mediators and their relative strength (effect size and confidence intervals). We controlled for age and gender as covariates. We used bootstrapping sampling $(n=5000)$ distributions to calculate the direct and indirect effects and confidence intervals (95\%) of the estimated effects. The point estimate is considered significant when the confidence interval does not contain zero.

Additionally, to assess whether the measurement model (confirmatory factor analysis Model of the scale), as well as the structural path models, are invariant across genders, religious affiliations (Christian and Muslims), and regions (Upper Egypt, Middle Egypt, and Cairo), we conducted multi-group invariance analysis (Sarstedt, Henseler, \& Christian, 2011; Meade, Johnson, \& Braddy, 2008) (hypothesis 2). Four nested models were tested sequentially: a configural invariance model, a metric invariance model, a scalar invariance model, and a strict invariance model. In the configural model, (i.e., identical form), the parameters are all freely estimated across groups. Configural invariance assumes that the same theoretical model holds across all relevant groups (e.g., van de Schoot, Lugtig, \& Hox, 2012). In the metric model (i.e., weak or partial invariance), the parameters are constrained to be identical across groups. In the scalar model or "strong invariance," variables and paths variances are set to be equal across groups. Lastly, the strict model "strict invariance" additionally constrains the residuals to be the same across the three groups. Although there is broad acceptance of the steps for testing measurement invariance, the criteria for evaluating the invariance of the models at each level are not as clear. Chi-square tests LRT is highly sensitive to sample size (e.g., Meade \& Lautenschlager, 2004), potentially leading to an excessively conservative test of invariance and is controversial to be used with large samples (our sample size: $\mathrm{N}=490$ ). Byrne, Shavelson, \& Muthén, 1989, have argued that invariance can be established when two indicators are invariant. According to Chen (2007), the null hypothesis of invariance should not be rejected when changes in CFI are less than or equal to 0.01 and in RMSEA are less than or equal to 0.015 .

Further, to explore the nature of the association between physical EAA (fear of death) that needed more in-depth analysis of its dynamics that eluded the conceptual model's assumptions, we conducted curve estimation regression to 
explore its potential non-linear relationships with relevant variables and its relative effect size. Further, we explored using the same procedure the non-linear association between other EAA dimensions (Collective, psychic, and status) and other trauma variables (Hypothesis 5).

\section{Results}

Exploratory and confirmatory factor analysis results (Construct Validity):

Using the Egyptian first sub-sample $(\mathrm{N}=245)$, exploratory factor analysis, principal axis factoring (PAF) with oblique rotation produced a four-factor solution that accounted for 66.64 of the variance. The first factor accounted for 38.93 of the variance with Eigenvalue of 5.84 and loaded on the items that represented identity status EAA (5 items). The second factor accounted for 10.64 of the variance with Eigenvalue of 1.60 and loaded on the items that represented collective identity EAA (4 items). The third factor accounted for 9.41 of the variance with Eigenvalue of 1.41 and loaded on the items that represented personal (psychic) EAA (3 items). The fourth factor accounted for 7.66 of the variance with Eigenvalue of 1.15 and loaded on the items that represented physical EAA or fear of death ( 3 items). The four factors accounted for $66.64 \%$ of the variance and exceeded the 95th percentile of eigenvalues of factors derived from random data using parallel analysis (O'Connor, 2000). Table 1 contains the Means, Standard Deviations and communalities, and loading of each item.

Using the second Egyptian sub-sample $(\mathrm{N}=245)$ and the UK sample $(\mathrm{N}=$ 178), we conducted separate confirmatory factor analyses (using weighted least squares estimation) for the four-factor solution on each. The model fit nicely in both sub-samples (For the UK sample: Chi-Square $=215.852$, d.f. $=81, p=$ 0.000 , CFI $=0.957$, RMSEA $=0.058$ ). Because the correlations between the four factors were high (between 0.49 and 0.60 ), we conducted a secondary confirmatory factor analysis, with EAA as a single second-order factor. The model fitted well (in both samples) before modifications, and few correlated errors improved the fit further (For the UK sample: Chi-Square $=115.806$, d.f. $=81, p=0.007$, $\mathrm{CFI}=0.973$, RMSEA $=0.049$ ). An examination of the items shows a fair amount of similarity in wording and suggests that these items may be tapping an unintended secondary characteristic which justified adding correlated errors between some items. Figure 1 provides the confirmatory second order analysis for the UK sample. The results of exploratory and confirmatory factor analysis confirmed the scale structural validity across two different cultures (Egyptians and British) as a unitary second-order factor with four significantly correlated first-order factors. The results supported the first hypothesis proposition of the structural/construct validity of the measure.

Developing a new short form of EAA scale (optional for use by researchers and clinicians)

Based on the results of exploratory factor analysis, we chose the item with the highest loading on each of the four factors to construct a short form of the scale 
Table 1. The mean, standard deviation and communalities, and loading of each item of the existential annihilation scale on the four extracted factors in the Egypt sample.

\begin{tabular}{|c|c|c|c|c|c|c|}
\hline \multirow{2}{*}{ Items Abbreviated (see Appendix 1 for the full items) } & \multirow{2}{*}{$\mathrm{M}(\mathrm{SD})$} & \multirow{2}{*}{ Comm. } & \multicolumn{4}{|c|}{ Factors } \\
\hline & & & 1 & 2 & 3 & 4 \\
\hline My loss of job/ business made me feel worthless & $0.80(0.98)$ & 0.649 & 0.780 & 0.006 & -0.021 & 0.062 \\
\hline Being disadvantaged because of unequal or lower status... & $0.73(0.90)$ & 645 & 0.755 & 0.006 & 0.013 & 0.052 \\
\hline Belonging to an impoverished family, or being myself poor. & $0.81(0.99)$ & 0.581 & 0.657 & -0.035 & -0.012 & -0.026 \\
\hline My previous or current failure in school... & $0.93(1.06)$ & 0.546 & 0.618 & -0.017 & 0.015 & -0.055 \\
\hline My previous or current loss of one of my life assets... & $0.84(1.01)$ & 0.585 & 0.588 & -0.023 & 0.012 & -0.167 \\
\hline Racism, oppression, discrimination... & $1.03(1.14)$ & 0.810 & 0.005 & -0.920 & -0.053 & 0.000 \\
\hline One of my groups has been threatened & $1.03(1.10)$ & 0.768 & -0.008 & -0.826 & -0.088 & -0.063 \\
\hline Sometimes I feel the threat of extermination & $0.92(1.10)$ & 0.639 & 0.069 & -0.520 & 0.293 & 0.019 \\
\hline I feel personally threatened... & $1.61(1.56)$ & 0.514 & 0.061 & -0.491 & 0.127 & 0.008 \\
\hline The serious violations of me & $1.25(1.07)$ & 0.725 & 0.052 & 0.049 & 0.775 & -0.007 \\
\hline Being fragmented unable to cope & $1.17(1.06)$ & 0.729 & -0.016 & -0.096 & 0.768 & 0.044 \\
\hline I sometimes worry that I just lose my sense of self & $1.48(1.07)$ & 0.668 & -0.022 & 0.008 & 0.660 & -0.103 \\
\hline I am terrified of death. & $0.77(.98)$ & 0.800 & -0.043 & -0.066 & -0.032 & --0.876 \\
\hline I worry about my death & $0.87(1.02)$ & 0.777 & 0.006 & 0.010 & 0.044 & -0.808 \\
\hline I think a lot about my death. & $0.9(1.06)$ & 0.559 & 0.180 & 0.012 & 0.084 & -0.461 \\
\hline
\end{tabular}

Note: Comm. $=$ Communalities, $\mathrm{M}(\mathrm{SD})=$ Mean $($ standard Deviation $)$.

(see Appendix 1). Each item has good single item reliability (its loading on the factor as well as its communality) and can be used as a reliable single item measure for the type of EAA that represents (Wanous \& Hudy, 2001). The correlation between the four items short measure and the full scale was 0.925 in the Egyptian sample, and 0.939 in the UK sample. Internal consistency alpha for the short measure was 0.70 in the UK sample, and 0.69 in the Egyptian sample. Test-retest ( 4 weeks interval) on a sample of 34 found a correlation of 0.95 between time 1 and time 2, which indicated good stability (see Appendix 2).

\section{Measurement Invariance of EAA Scale in the Egyptian and the UK sample}

In the Egyptian sample, multigroup measurement invariance indicated that the confirmatory measurement model and the second-order structure of EAA are strictly invariant between genders, religious groups (Muslims and Christians), age groups (adults and adolescents), and between geographical regions (Upper Egypt, Middle Egypt, and Cairo). The model was strictly invariant across genders in the UK sample Table 2 included the measurement and structural fit indexes on the six levels (unconstrained, measurement weights, structural weights, structural covariance, structural residuals, and measurement residuals) for each analysis which did not significantly differ from each other according to the criteria discussed in the analysis section. The results supported the second hypothesis of the measurement invariance of the scale. 


\section{$\mathrm{N}=178$ (UK sample) \\ Chi Square $=115.806$. d.f. $=81, p=0.007$ \\ $\mathrm{CFI}=0.973$ \\ RMSEA $=0.049$}

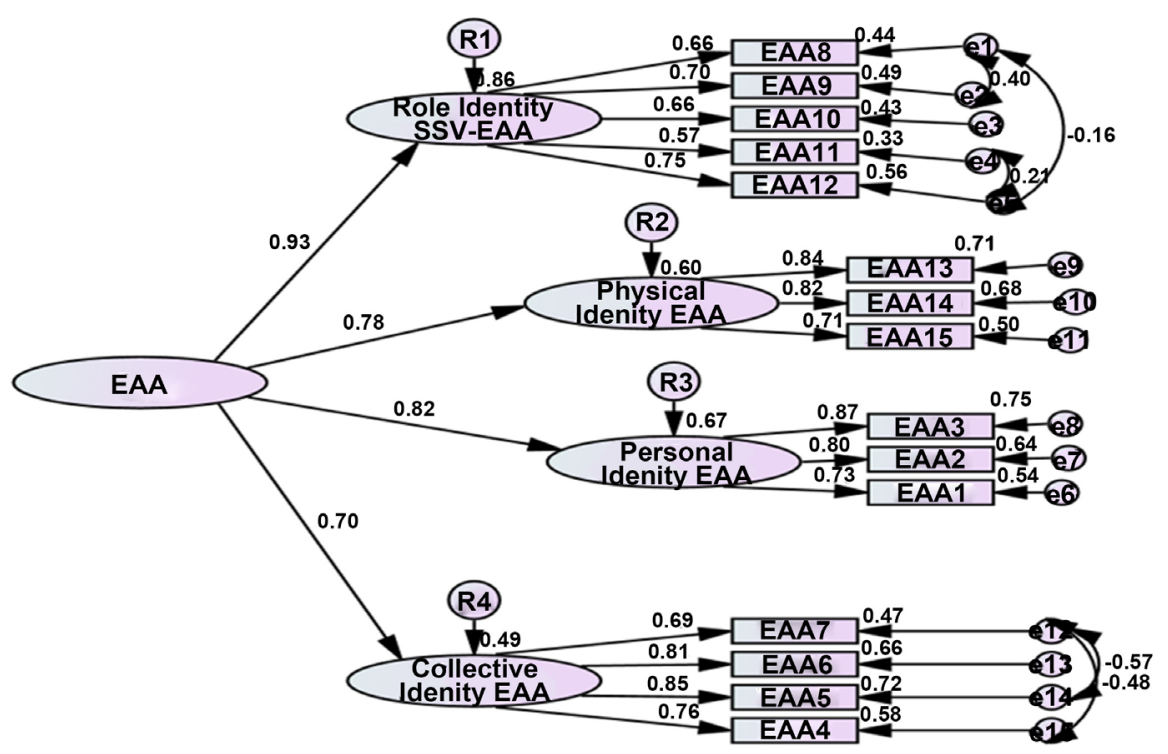

Figure 1. Second order confirmatory factor analysis for existential anxiety scale on the United Kingdom sample. Note: EAA = Existential Annihilation Anxiety, Role Identity SSV-EAA $=$ Social-structural violence and role identity EAA.

\section{Reliability and stability}

In the Egyptian sample, Alpha for the total scale was 0.89. Alpha for personal identity EAA was 0.79 , and 0.83 for collective identity EAA. For status identity, EAA alpha was 0.83 , and 0.80 for physical identity EAA (fear of death). In the UK sample, Alpha for the total scale was 0.92 . It was 0.84 for personal identity EAA, and 0.86 for collective identity EAA. It was 0.82 for status identity EAA, and. 83 for physical identity EAA (fear of death). Test-retest (4 weeks interval) on a sample of 34 found a correlation of 0.97 between time 1 and time 2, which indicated excellent stability. The results supported the first hypothesis premises of reliability and stability of the scale.

\section{Correlational results}

EAA had a significant association with collective identity, personal identity, attachment, and role (status achievement) identity traumas, and gender discrimination, in both samples and with physical/survival, and secondary trauma in the UK sample. Identity status EAA had higher associations with role (status achievement) trauma. Collective identity EAA had higher associations with collective identity traumas and gender discriminations. Personal identity EAA had a higher association with personal identity traumas in both samples.

EAA had a significant association with identity salience, entrapment, and existential quest (uncertainty), in the UK sample. EAA had a significant high 
Table 2. Multigroup measurement invariance analyses between groups in Egypt and the UK samples.

\begin{tabular}{|c|c|c|c|c|c|c|c|}
\hline \multicolumn{8}{|c|}{ Multi-group Measurement Invariance between genders in the Egyptian Sample } \\
\hline & Chi-square & $d f$ & $p$ & chi-squarel $d f$ & CFI & RMSEA & IFI \\
\hline Unconstrained & 330.864 & 166 & 0.000 & 10.993 & 0.948 & 0.045 & 0.949 \\
\hline Measurement weights & 340.205 & 177 & 0.000 & 10.922 & 0.949 & 0.043 & 0.949 \\
\hline Structural weights & 341.761 & 180 & 0.000 & 10.899 & 0.949 & 0.043 & 0.950 \\
\hline Structural covariance & 341.831 & 181 & 0.000 & 10.889 & 0.949 & 0.043 & 0.950 \\
\hline Structural residuals & 346.699 & 185 & 0.000 & 10.874 & 0.949 & 0.042 & 0.950 \\
\hline Measurement residuals & 376.471 & 203 & 0.000 & 10.855 & 0.945 & 0.042 & 0.946 \\
\hline \multicolumn{8}{|c|}{ Multi-group invariance between adults and adolescents in the Egyptian Sample } \\
\hline Unconstrained & 363.361 & 166 & 0.000 & 20.189 & 0.938 & 0.049 & 0.939 \\
\hline Measurement weights & 375.642 & 177 & 0.000 & 20.122 & 0.938 & 0.048 & 0.938 \\
\hline Structural weights & 379.410 & 180 & 0.000 & 20.108 & 0.938 & 0.048 & 0.938 \\
\hline Structural covariance & 379.468 & 181 & 0.000 & 20.097 & 0.938 & 0.047 & 0.938 \\
\hline Structural residuals & 385.380 & 185 & 0.000 & 20.083 & 0.937 & 0.047 & 0.938 \\
\hline Measurement residuals & 420.707 & 203 & 0.000 & 20.072 & 0.932 & 0.047 & 0.932 \\
\hline \multicolumn{8}{|c|}{ Multigroup Invariance between genders in the United Kingdom Sample } \\
\hline Unconstrained & 260.987 & 162 & 0.000 & 10.611 & 0.930 & 0.059 & 0.932 \\
\hline Measurement weights & 274.463 & 173 & 0.000 & 10.586 & 0.928 & 0.058 & 0.930 \\
\hline Structural weights & 284.823 & 176 & 0.000 & 10.618 & 0.923 & 0.059 & 0.925 \\
\hline Structural covariance & 284.921 & 177 & 0.000 & 10.610 & 0.924 & 0.059 & 0.926 \\
\hline Structural residuals & 296.622 & 181 & 0.000 & 10.639 & 0.920 & 0.060 & 0.920 \\
\hline Measurement residuals & 347.325 & 201 & 0.000 & 10.728 & 0.910 & 0.064 & 0.916 \\
\hline
\end{tabular}

association with psychopathology, PTSD, depression, internalizing, externalizing, thought disorder, suicidality and poor health in both samples. EAA had a negative association with the will to live, self-esteem, in both samples. Socio-economic status had negative associations with EAA and had a higher negative association with identity status EAA. Identity salience had a higher and significant association with collective EAA. Attachment trauma had a significant association with psychic EAA in both samples. The subscales of EAA had similar positive and negative associations, with mental health, will to live and self-esteem as the total scale.

Correlational results provided evidence of the measure's adequate convergent, divergent and predictive validity in both the Western and non-Western samples. The measure and its subscales had a highly significant association with the constructed four items EAA short measure and the previously validated EAA-3 items measure in both samples. The results supported the first hypothesis premises of EAA associations, as well as hypothesis 4 for the potential role will to exist and self-esteem. Table 3 details these correlations. 
Table 3. Zero ORDER Correlations between EAA and its four subscales and selective variables in the UK and Egyptian samples.

\begin{tabular}{|c|c|c|c|c|c|c|c|c|c|c|}
\hline \multicolumn{6}{|c|}{ The UK Sample } & \multicolumn{5}{|c|}{ The Egyptian Sample } \\
\hline & $\begin{array}{l}\text { EAA } \\
\text { (Total) }\end{array}$ & $\begin{array}{l}\text { Status } \\
\text { EAA }\end{array}$ & $\begin{array}{c}\text { Collective } \\
\text { EAA }\end{array}$ & $\begin{array}{c}\text { Psychic } \\
\text { EAA }\end{array}$ & $\begin{array}{c}\text { Physical } \\
\text { EAA }\end{array}$ & EAA & $\begin{array}{l}\text { Status } \\
\text { EAA }\end{array}$ & $\begin{array}{c}\text { Collective } \\
\text { EAA }\end{array}$ & $\begin{array}{c}\text { Psychic } \\
\text { EAA }\end{array}$ & $\begin{array}{c}\text { Physical } \\
\text { EAA }\end{array}$ \\
\hline GD & $0.21^{* *}$ & $0.18^{*}$ & $0.23^{\star *}$ & $0.18^{\star}$ & 0.09 & $0.18^{\star * \star}$ & $0.11^{\star *}$ & $0.15^{\star * *}$ & $0.17^{\star * *}$ & $0.11^{\star \star}$ \\
\hline PIT & $0.25^{* * *}$ & $0.24^{\star *}$ & $0.16^{*}$ & $0.22^{\star *}$ & $0.19^{*}$ & $0.08+$ & 0.01 & 0.05 & $0.14^{* * *}$ & 0.050 \\
\hline CIT & $0.20^{* *}$ & $0.21^{\star \star}$ & $0.20^{* *}$ & 0.11 & 0.11 & $0.14^{\star * *}$ & 0.04 & $0.21^{* *}$ & $0.10^{*}$ & 0.071 \\
\hline Attachment Traumas & $0.14^{*}$ & $0.14^{*}$ & 0.03 & $0.15^{\star}$ & 0.12 & 0.07 & 0.01 & 0.07 & $0.08^{*}$ & 0.05 \\
\hline RIT & $0.17^{\star}$ & $0.22^{\star * *}$ & $0.16^{*}$ & 0.12 & 0.01 & $0.14^{* * *}$ & $0.18^{* * *}$ & 0.07 & $0.10^{*}$ & 0.06 \\
\hline Survival Trauma & $0.14^{*}$ & 0.11 & 0.12 & 0.10 & $0.14^{*}$ & -0.013 & -0.006 & -0.021 & 0.002 & -0.013 \\
\hline Secondary Traumas & $0.21^{\star *}$ & $0.19^{\star *}$ & 0.13 & $0.18^{\star *}$ & $0.18^{*}$ & -0.001 & -0.004 & 0.034 & 0.000 & -0.047 \\
\hline Depression & $0.35^{* * *}$ & $0.31^{\star \star \star}$ & 0.12 & $0.44^{\star \star \star}$ & $0.24^{* * *}$ & $0.31^{\star * *}$ & $0.26^{* * *}$ & $0.21^{* * *}$ & $0.23^{* * *}$ & $0.25^{* * *}$ \\
\hline PTSD & $0.51^{* * *}$ & $0.48^{\star * *}$ & $0.26^{* * *}$ & $0.48^{* * *}$ & $0.40^{* * *}$ & $0.41^{\star * *}$ & $0.32^{* * *}$ & $0.30^{* * *}$ & $0.31^{\star * *}$ & $0.34^{* * *}$ \\
\hline Psychopathology & $0.48^{* * *}$ & $0.48^{\star * *}$ & $0.32^{* * *}$ & $0.41^{\star * *}$ & $0.32^{* * *}$ & $0.58^{\star * *}$ & $0.48^{* * *}$ & $0.43^{* * *}$ & $0.42^{* *}$ & $0.44^{\star \star}$ \\
\hline Internalizing & $0.47^{* * *}$ & $0.43^{* * *}$ & $0.25^{* * *}$ & $0.49^{* * *}$ & $0.35^{* * *}$ & $0.40^{* * *}$ & $0.31^{* * *}$ & $0.31^{* * *}$ & $0.33^{\star * *}$ & $0.29^{* * *}$ \\
\hline Externalizing & $0.26^{* * *}$ & $0.30^{\star * *}$ & $0.27^{* * *}$ & 0.12 & 0.12 & $0.45^{\star * *}$ & $0.43^{* * *}$ & $0.31^{* * *}$ & $0.26^{* * *}$ & $0.36^{* * *}$ \\
\hline Thought Disorder & $0.42^{* * *}$ & $0.43^{\star * *}$ & $0.26^{* * *}$ & $0.36^{* * *}$ & $0.28^{\star * *}$ & $0.51^{\star * *}$ & $0.40^{* * *}$ & $0.38^{* * *}$ & $0.40^{* * *}$ & $0.40^{* * *}$ \\
\hline Suicidality & $0.25^{* * *}$ & $0.25^{\star * *}$ & $0.14^{*}$ & $0.23^{\star * *}$ & $0.19^{* *}$ & $0.30^{* * *}$ & $0.25^{* * *}$ & $0.20^{* * *}$ & $0.21^{* * *}$ & $0.25^{* * *}$ \\
\hline Poor Health & $0.40^{* * *}$ & $0.34^{\star * *}$ & $0.22^{* * *}$ & $0.36^{\star * *}$ & $0.40^{* * *}$ & $0.12^{\star}$ & 0.07 & 0.08 & $0.13^{* *}$ & $0.11^{\star}$ \\
\hline CIS & $0.22^{* * *}$ & $0.17^{\star}$ & $0.35^{* * *}$ & 0.073 & 0.13 & 0.03 & -0.02 & $0.13^{\star * *}$ & 0.02 & -0.06 \\
\hline Entrapment & $0.55^{* * *}$ & $0.59^{\star * *}$ & $0.27^{* * *}$ & $0.51^{* * *}$ & $0.36^{* * *}$ & NM & NM & NM & NM & NM \\
\hline Existential Quest & $0.37^{* * *}$ & $0.38^{\star \star *}$ & $0.19^{\star *}$ & $0.32^{\star * *}$ & $0.30^{* * *}$ & NM & NM & NM & NM & NM \\
\hline SES & $-0.28^{\star \star}$ & $-0.39^{\star * *}$ & $-0.17^{\star}$ & $-0.15^{*}$ & -0.11 & $-0.09^{*}$ & $-0.12^{\star *}$ & 0.07 & 0.04 & 0.02 \\
\hline Will to Exist/Live & $-0.40^{\star * *}$ & $-0.39^{* * *}$ & $-0.22^{\star * *}$ & $-0.39^{\star * *}$ & $-0.26^{* * *}$ & $-0.26^{* * *}$ & $-0.26^{* * *}$ & $-0.16^{\star * *}$ & $-0.22^{\star * *}$ & $-0.15^{\star * *}$ \\
\hline Self-esteem & $-0.32^{\star * \star}$ & $-0.34^{* * *}$ & -0.087 & $-0.40^{\star * *}$ & $-0.18^{\star}$ & $-0.36^{* * *}$ & $-0.36^{* * *}$ & $-0.23^{\star * \star}$ & $-0.29^{\star * *}$ & $-0.21^{\star * *}$ \\
\hline EAA short form-3 & $0.84^{\star * *}$ & $0.63^{* * *}$ & $0.83^{* * *}$ & $0.78^{* * *}$ & $0.53^{* * *}$ & $0.83^{\star * *}$ & $0.48^{* * *}$ & $0.84^{* * *}$ & $0.75^{* * *}$ & $0.44^{* * *}$ \\
\hline EAA short form-4 & $0.94^{\star * \star}$ & $0.78^{\star \star \star}$ & $0.76^{\star * *}$ & $0.78^{\star \star *}$ & $0.72^{\star \star \star}$ & $0.93^{\star * *}$ & $0.71^{\star * *}$ & $0.75^{\star * *}$ & $0.69^{* * *}$ & $0.69^{\star \star \star}$ \\
\hline
\end{tabular}

Note: NM = not measured in this sample, SES= Socio-Economic Status, CIS = Collective Identity Salience, GD = Gender Discrimination, PIT = Personal Identity Traumas, RIT $=$ Role identity Traumas, CIT $=$ Collective Identity Traumas. Note: EAA short form -4 correlation with total scale was calculated after removing the items used in the short forms from the long form prior to calculating the correlation. Note: Note. ${ }^{*} p<0.05,{ }^{* *} p<0.01,{ }^{* * *} p<0.001$.

\section{Path analysis and PROCESS mediation Results}

To test the hypothesis that EAA significantly mediates the effects of cumulative life traumas, as well as directly impact psychopathology, we tested a path model in which cumulative trauma predicted EAA, and EAA impacted directly and mediated the effects of cumulative trauma on psychopathology. The model fitted well in both the Egyptian and the UK data. Cumulative trauma found to have only indirect effects on psychopathology via EAA. However, the direct effects of EAA on psychopathology accounted for higher effect size than its mediated effects. The centrality and effect size of EAA on psychopathology was significant. The results supported hypothesis 3-A, concerning the direct and me- 
diated effects of EAA. Figure 2 describes the direct effects of the variables in the model and provides the model fit parameters. Table 4 provides the direct, indirect and total effects of each variable in both the Egyptian and the UK sample.

To test the hypothesis (hypothesis 3-B) that each type of trauma predicts the respective type of EAA, PROCESS analysis of the Egyptian Sample was conducted for the effects of each trauma type on the respective EAA, controlling for gender age and geographical location. Results found, as predicted, that role identity trauma predicted status identity EAA directly and indirectly via collective EAA. Collective identity traumas predicted directly collective EAA, without significant indirect mediators. Personal identity traumas predicted directly personal/Psychic EAA without significant mediators. However, survival trauma did not predict directly or indirectly death anxiety. Similar results were found in the UK sample. The results partly supported hypothesis $3-B$. Table 5 details these results for the Egyptian sample.

Curve Estimation Regression for the associations of Physical identity EAA (PI-EAA) (i.e., fear of death)

While the results supported the hypothesis that each respective trauma type predicts the relevant EAA type for personal identity trauma, status identity trauma, and collective identity trauma, they did not support the hypothesis concerning the effects of survival trauma on physical EAA. We decided to conduct additional analysis to explore the contributing factors to physical EAA (PI-EAA) (i.e., terror and fear of physical death). We conducted curve estimation regression between PI-EAA and different related variables:

In the UK sample, PI-EAA was associated with Status identity EAA linearly (F $=73.09, p<0.000, \mathrm{R}$ square $=0.293)$, and non-linearly (the quadratic model $)(\mathrm{F}$ $=40.16, p<0.000$, $\mathrm{R}$ square $=0.315$ ). The non-linear model accounted for more variance. PI-EAA was associated with Psychic EAA linearly $(\mathrm{F}=77.13, p<$ $0.000, \mathrm{R}$ square $=0.305)$, and non-linearly (the cubic model $)(\mathrm{F}=28.65, p<$ $0.000, \mathrm{R}$ square $=0.331)$, with the non-linear model accounted for more variance. PI-EAA was associated with Collective EAA linearly $(\mathrm{F}=42.00, p<$ $0.000, \mathrm{R}$ square $=0.193)$, and non-linearly (the cubic model $)(\mathrm{F}=13.99, p<$ $0.000, \mathrm{R}$ square $=0.194)$. The linear and non-linear models accounted for equal variances.

PI-EAA was associated with poor physical health linearly ( $\mathrm{F}=32.78, p<$ 0.000 , $\mathrm{R}$ square $=0.157)$, and non-linearly (the quadratic model $)(\mathrm{F}=16.37, p<$ 0.000 , R square $=0.158)$. The linear and non-linear models accounted for equal variances. PI-EAA was associated with cumulative trauma linearly $(\mathrm{F}=4.52, p<$ 0.023 , R square $=0.035)$, and non-linearly (the quadratic model $)(\mathrm{F}=6.91, p<$ 0.001 , $\mathrm{R}$ square $=0.077)$, with the non-linear model accounted for more variance. PI-EAA was not associated with survival trauma linearly or non-linearly. PH-EAA was associated with personal identity traumas (physical and sexual abuse) linearly $(\mathrm{F}=6.28, p<0.014$, $\mathrm{R}$ square $=0.034)$, and non-linearly (the quadratic model $)(\mathrm{F}=5.38, p<0.78005, \mathrm{R}$ square $=0.058)$, with the non-linear 


\section{$\mathrm{N}=490$ \\ Chi Square $=0.012$, d.f. $=1, p=0.913$ \\ $\mathrm{CFI}=1.000$ \\ RMSEA $=0.000$}

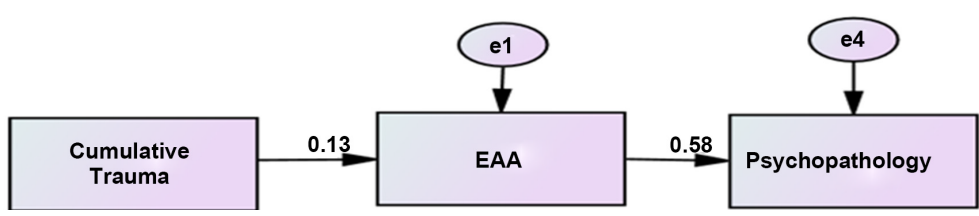

Figure 2. Path model for the direct effects of cumulative stress and traumas and existential annihilation anxiety on psychopathology.

Table 4. The direct, indirect and total effects of Cumulative traumas and existential annihilation anxiety on psychopathology in the Egyptian and the UK samples.

\begin{tabular}{|c|c|c|c|c|}
\hline \multicolumn{3}{|c|}{ Egyptian Sample } & \multicolumn{2}{|c|}{ UK Sample } \\
\hline \multirow{2}{*}{ Causal Variables } & \multicolumn{4}{|c|}{ Endogenous Variables } \\
\hline & EAA & Psychopathology & EAA & Psychopathology \\
\hline \multicolumn{5}{|c|}{ Cumulative Trauma } \\
\hline Direct Effects & $\begin{array}{c}0.13^{\star *} \\
(0.05 / 0.21)\end{array}$ & - & $\begin{array}{c}0.23^{\star} \\
(0.06 / 0.35)\end{array}$ & $\overline{ }$ \\
\hline Indirect Effects & - & $\begin{array}{c}0.07^{* *} \\
(0.03 / 0.12)\end{array}$ & $\bar{x}$ & $\begin{array}{c}0.11^{* *} \\
(0.03 / 0.20)\end{array}$ \\
\hline Total Effects & $\begin{array}{c}0.13^{* *} \\
(0.05 / 0.21)\end{array}$ & $\begin{array}{c}0.07^{* *} \\
(0.03 / 0.12)\end{array}$ & $\begin{array}{c}0.23^{\star} \\
(0.06 / 0.35)\end{array}$ & $\begin{array}{c}0.11^{\star *} \\
(0.03 / 0.20)\end{array}$ \\
\hline \multicolumn{5}{|c|}{ Existential Annihilation Anxiety (EAA) } \\
\hline Direct Effects & & $\begin{array}{c}0.58^{\star *} \\
(0.50 / 0.63)\end{array}$ & & $\begin{array}{c}48^{\star *} \\
(0.33 / 0.63)\end{array}$ \\
\hline Indirect Effects & - & - & - & - \\
\hline Total Effects & - & $\begin{array}{c}0.58^{\star *} \\
(0.50 / 0.63)\end{array}$ & & $\begin{array}{c}0.48^{* *} \\
(0.33 / 0.63)\end{array}$ \\
\hline Squared R & 0.016 & 0.316 & 0.051 & 0.233 \\
\hline
\end{tabular}

Notes: ${ }^{\star} p<0.05,{ }^{* *} p<0.01,{ }^{* * *} p<0.001$.

model accounted for more variance. Similar results were found in the Egyptian sample.

Further, conducting curve estimation regression for the association between the other three EAA dimensions (psychic, collective and status EAA) and trauma and health variables indicated the superiority of the non-linear model in most associations in the UK and Egyptian samples. Future studies should explore in more depth the non-linear dynamics of EAA using advanced non-linear techniques that explore the thresholds of reaching the clinical significance of its impact, such as chained Cusp catastrophe model (Guastello \& Liebovitch, 2009). 
I. Kira et al.

Table 5. The effects of different trauma types, its mediators, and covariates on EAA types.

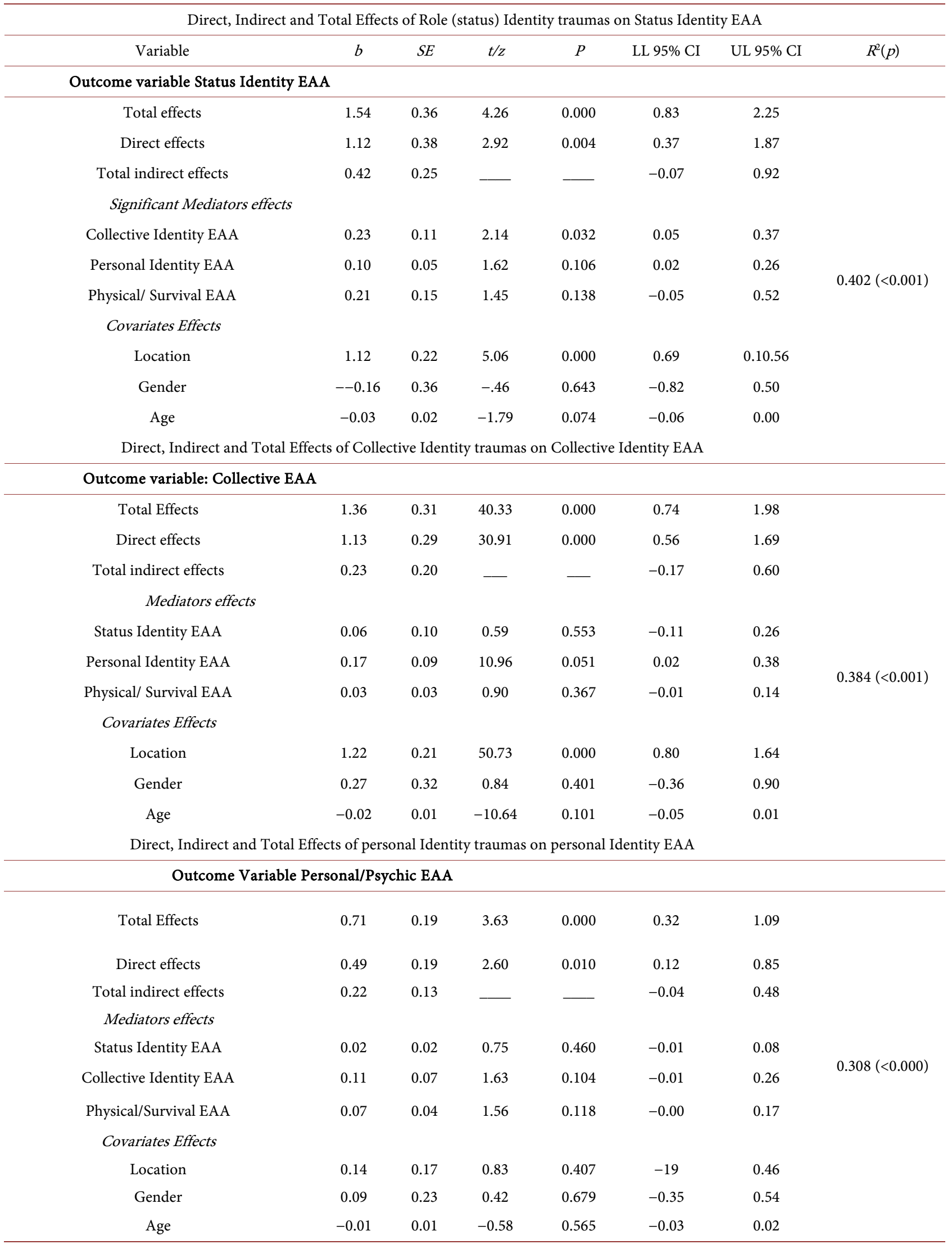




\section{Cut-off Critical Scores and the Differences between Groups in EAA:}

The mean EAA scale was 9.97, with SD of 8.88 (maximum score was 38 ) in the UK sample. The mean EAA scale was 15.22, with SD of 9.77 (maximum score was 40) in the Egypt sample. EAA scores and its subscales were significantly much higher in the Egyptian sample, especially in the collective EAA subscale $((\mathrm{M}=4.59$ ( $\mathrm{SD}=3.64)$ in the Egypt sample, and $1.83(\mathrm{SD}=2.50)$ in the UK sample). There were no significant gender differences in EAA in both samples.

For the total scale, eighty percentiles scored at 18.48 in the UK sample, while the same percentile scored at 24.13 in the Egyptian sample. While establishing a cut-off point for clinical significance that brings a concern should be established using clinical versus non-clinical samples, we recommend at this point to use the critical cut-off point of 21 or more, which is at above 75 percentile in the Egyptian sample and at or above .85 percentile in the UK sample. This cut-off score should be considered as a provisional cut-off point until a cut-off point is verified or established in clinical practice or future clinical studies. Mapping the scores in each sub-scale and identifying cut-off scores for each scale should map the types of EAA that are high and need to be addressed in intervention.

\section{Discussion}

We developed a conceptual model of identity-based existential anxiety and translated the model into a scale of EAA that measures the model four components. We assessed the developed scale and the model related assumptions. Results provided convincing evidence of structural (construct), convergent, and divergent validity, as well as the internal consistency and the stability of EAA scale and it subscales over time and across two different Western and nonWestern cultures. Further, the measurement model was strictly invariant across groups in both samples. The measure had good structural and predictive validity. EAA, as measured by the scale mediated the effects of cumulative trauma, and directly impacted psychopathology. However, the impact of EAA is not only the outcome of its mediation of the impact of cumulative trauma. The direct effects of EAA on psychopathology accounted for higher effect size than its mediated effects. There seem to be other internal processes and contributing factors that play to amplify EAA impact beyond its simple mediation of the effects of cumulative traumas. For example, different EAA types intersect and amplify each other, and alter appraisal, reappraisal and the final perception of the existential anxiety arousing events.

While the results confirmed the prediction that each relevant identity trauma type predicts the respective type of EAA, in the cases of status EAA, psychic EAA, and collective EAA, that was not true for death anxiety. Physical survival trauma was significantly correlated with physical survival EAA in the UK sample only but did not predict it in either sample using PROCESS analysis or path models. Death fear while was significantly predictive of psychopathology, and belong to the construct of existential anxieties and related to existential threats, seems to emanate more from internal cognitive and arousal processes, than from 
a trauma per se. The most significant variables that contributed to physical EAA were the other types of EAA that amplified its initial power and impact. Further, curve-estimation regression clarified this point, as the relationships between cumulative trauma and physical EAA (terror of death) was more non-linear. The non-linear systemic dynamics between EAA different components with its different amplification feedback and forward loops seems to play a substantial and significant role in its impact. The highest association with PI-EAA, excluding its intersections with other EAA types was poor physical health conditions that naturally raise existential concerns about physical survival. While the intersection effects with other EAA types seem more non-linear, its robust association with poor physical health seems to be a more linear association. More conceptual modifications of our model and further studies are needed to clarify these unexpected results from a non-linear systemic perspective.

\section{Implications for Clinical Science}

While the current study provided a new long and short measures for EAA that are valid, reliable and invariant and can be used to measure and screen for EAA, it pointed out to the need for a paradigm shift in clinical science from a restricted study of general anxiety, to a more focused (or added) approach on assessing different intersected types of EAA, and exploring interventions that address their mental health impact.

The mental health impact of the existential threat to one or more of the person's multiple identities need to be convincingly addressed in intervention. Existential threats are the most distressing and significantly contribute to the health and mental health. Current interventions do not address the roots and outcomes of existential dynamics and offer disappointing results (e.g., Steenkamp, Litz, Hoge, \& Marmar, 2015).

In this enterprise, we expanded the conceptual domain of existential identity threats, to integrate the hard to measure theoretical, psychoanalytic, and sociological models, in a measurable, empirically valid and clinically addressable constructs. That should help to future planning identity-focused interventions that work on alleviating such profound existential concerns that severely impact the person's health and well-being. The new paradigm that focuses on identity linear and non-linear dynamics may move the field forward beyond the current single traumas clinical models.

Further, the current findings emphasized the significance of dynamics of will to exist, live, survive (and thrive), and the importance of self-evaluation dynamics in the therapeutic process, and their potential to be part of the comprehensive identity and existential anxiety-focused interventions. The new paradigm provides a new opportunity for clinicians to utilize its potential to design identity and existential anxiety-based intervention and prevention components that can be utilized as a stand-alone, or included in their repertoire to help clients. Alleviating EAA through different interventions that target "will to exist," and self-evaluation, among other self and identity focused interventions, have strong 
potential to trigger different positive dynamics to enhance mental health and advance the well-being of clients. Future clinical efforts may design 10 - 12 sessions of identity and existential anxiety-based intervention and prevention programs, that can be delivered individually or in a group format. Their potential effectiveness can be tested in controlled trials.

\section{Limitations of the Study}

The current study, which provides significant potential contributions to measuring existential anxieties and understanding its dynamics from a broader perspective, has several limitations. One of the limitations is that the study used mostly convenient samples that may have limited and biased representation. We recommend more studies that use more representative samples. Another limitation is that the measures we used are based on participants' self-reports, which could be subject to under- or over-reporting of events due to current symptoms, embarrassment, shame, or social desirability. Additionally, while the measures we used have acceptable reliability, stability, and validity estimates, and we used standardized coefficients based on bootstrapping estimates of the direct and indirect effects, potential measurement error can still bias or attenuate estimates of the explained variance. Measurement error can make the predictors have less explanatory power.

Another limitation is that we utilized a cross-sectional design in testing our mediated model. Mediated models contain causal paths that inherently involve the passage of time and testing these paths with cross-sectional data can produce biased estimates (Maxwell \& Cole, 2007). Future studies may use longitudinal studies if feasible to retest the proposed model. Also, a cross-sectional design does not provide deterministic hard science models. Only probabilistic relationships can be drawn from the results. Deterministic causal relationships can be obtained using experimental designs if feasible. Accordingly, we should caution that the use of terms like direct, indirect and total effects should be understood as they are meant and intended by its use in path and PROCESS analyses. Despite these limitations, the results of the current study highlighted the strong probability of the damaging effects of existential annihilation anxieties. They emphasized the importance of a paradigm shift to identity- and existential based interventions, especially with those who are multiply traumatized.

\section{Conflicts of Interest}

The authors declare no conflicts of interest regarding the publication of this paper.

\section{References}

Adler, A. (1927). Individual Psychology. The Journal of Abnormal and Social Psychology, 22, 116-122. https://doi.org/10.1037/h0072190

Allen, R., Hurvich, M., \& Mcguire, H. (2017). Diagnostic Utility of the Hurvich Expe- 
rience Inventory/50. Psychoanalytic Psychology, 34, 271-278.

https://doi.org/10.1037/pap0000067

Berman, S. L., Weems, C. F., \& Stickle, T. R. (2006). Existential Anxiety in Adolescents: Prevalence, Structure, Association with Psychological Symptoms and Identity Development. Journal of Youth and Adolescence, 35, 285-292. https://doi.org/10.1007/s10964-006-9032-y

Bradley, R., Greene, J., Russ, E., Dutra, L., \& Westen, D. (2005). A Multidimensional Meta Analysis of Psychotherapy for PTSD. The American Journal of Psychiatry, 162, 214-227. https://doi.org/10.1176/appi.ajp.162.2.214

Burke, B. L., Martens, A., \& Faucher, E. H. (2010). Two Decades of Terror Management Theory: A Meta-Analysis of Mortality Salience Research. Personality and Social Psychology Review, 14, 155-195. https://doi.org/10.1177/1088868309352321

Byrne, B. M. (2012). A Primer of LISREL: Basic Applications and Programming for Confirmatory Factor Analytic Models. New York: Springer Science \& Business Media.

Chen, F. F. (2007). Sensitivity of Goodness of Fit Indexes to Lack of Measurement Invariance. Structural Equation Modeling, 14, 464-504.

https://doi.org/10.1080/10705510701301834

Christopher, J. C., \& Hickinbottom, S. (2008). Positive Psychology, Ethnocentrism, and the Disguised Ideology of Individualism. Theory \& Psychology, 18, 563-589. https://doi.org/10.1177/0959354308093396

Cohen, J. (1992). A Power Primer. Psychological Bulletin, 112, 155-159. https://doi.org/10.1037/0033-2909.112.1.155

Evans, G. W., Li, D., \& Whipple, S. S. (2013). Cumulative Risk and Child Development. Psychological Bulletin, 139, 1342-1396. https://doi.org/10.1037/a0031808

Festinger, L. (1954). A Theory of Social Comparison Processes. Human Relations, 7, 117-140. https://doi.org/10.1177/001872675400700202

Frankl, V. E. (1963). Man's Search for Meaning: An Introduction to Logotherapy. Oxford, UK: Washington Square Press.

Fuchs, T. (2013). Existential Vulnerability: Toward a Psychopathology of Limit Situations. Psychopathology, 46, 301-308. https://doi.org/10.1159/000351838

Griffiths, A. W., Wood, A. M., Maltby, J., Taylor, P. J., Panagioti, M., \& Tai, S. (2015). The Development of the Short Defeat and Entrapment Scale (SDES). Psychological Assessment, 27, 1182-1194. https://doi.org/10.1037/pas0000110

Guastello, S. J., \& Liebovitch, L. S. (2009). Introduction to Nonlinear Dynamics and Complexity. In S. J. Guastello, M. Koopmans, \& D. Pincus (Eds.), Chaos and Complexity in Psychology: The Theory of Nonlinear Dynamical Systems (pp. 1-40). New York, NY: Cambridge University Press.

Heidegger, M. (1927/1979). Being and Time. Tübingen: Max Niemeyer Verlag.

Hirschberger, G., Ein-Dor, T., Leidner, B., \& Saguy, T. (2016). How Is Existential Threat Related to Intergroup Conflict? Introducing the Multidimensional Existential Threat (MET) Model. Frontiers in Psychology, 7, 1877. https://doi.org/10.3389/fpsyg.2016.01877

Hurvich, M. (2004). Psychic Trauma and Fears of Annihilation. Living with Terror, Working with Trauma: A Clinician's Handbook (pp. 51-66). Latham, MD: Rowman and Littlefield.

Iverach, L., Menzies, R. G., \& Menzies, R. E. (2014). Death Anxiety and Its Role in Psychopathology: Reviewing the Status of a Transdiagnostic Construct. Clinical Psychology Review, 34, 580-593. https://doi.org/10.1016/j.cpr.2014.09.002 
Kierkegaard, S. (1849/1954b). The Sickness unto Death. Princeton, NJ: Princeton University Press.

Kira, I. (2001). Taxonomy of Trauma and Trauma Assessment. Traumatology, 2, 1-14. https://doi.org/10.1177/153476560100700202

Kira, I. (2002). Suicide Terror and Collective Trauma: A Collective Terror Management Paradigm. Chicago, IL: American Psychological Association Annual Convention. http://psycnet.apa.org/psycextra/316712004-001.pdf\&uid=316712004-001\&db=PE

Kira, I. (2006). Collective Identity Terror in the Israeli-Palestinian Conflict and Potential Solutions. In J. Kuriansky (Ed.), Terror in the Holy Land, inside the Anguish of Israeli-Palestinian Conflict (pp. 125-130). Westport, CT: Praeger.

Kira, I. A., Lewandowski, L., Chiodo, L., \& Ibrahim, A. (2014). Advances in Systemic Trauma Theory: Traumatogenic Dynamics and Consequences of Backlash as a Multi-Systemic Trauma on Iraqi Refugee Muslim Adolescents. Psychology, 5, 389-412. https://doi.org/10.4236/psych.2014.55050

Kira, I. A., Omidy, A. Z., \& Ashby, J. S. (2014). Cumulative Trauma, Appraisal, and Coping in Palestinian and American Indian Adults: Two Cross-Cultural Studies. Traumatology: An International Journal, 20, 119-133. https://doi.org/10.1037/h0099397

Kira, I. A., Shuwiekh, H., Kucharska, J., Fawzi, M., Ashby, J. S., Omidy, A. Z., Lewandowski, L. et al. (2018). Trauma Proliferation and Stress Generation (TPSG) Dynamics and Their Implications for Clinical Science. American Journal of Orthopsychiatry, 88 , 582-596. https://doi.org/10.1037/ort0000304

Kira, I. A., Shuwiekh, H., Rice, K., Al Ibraheem, B., \& Aljakoub, J. (2017). A Threatened Identity: The Mental Health Status of Syrian Refugees in Egypt and Its Etiology. Identity: An International Journal of Theory and Research, 17, 176-190. https://doi.org/10.1080/15283488.2017.1340163

Kira, I. A., Templin, T., Lewandowski, L., \& Shuwiekh, H. (2018). A Conceptual Model and Measurement of Identity-Based, Existential Annihilation Anxieties (EAA). Psychology, 9, 1306-1328. https://doi.org/10.4236/psych.2018.96080

Kira, I., Alawneh, A. N., Aboumediane, S., Mohanesh, J., Ozkan, B., \& Alamia, H. (2011). Identity Salience and Its Dynamics in Palestinians Adolescents. Psychology, 2, 781-791. https://doi.org/10.4236/psych.2011.28120

Kira, I., Alawneh, A., Aboumediene, S., Lewandowski, L., \& Laddis, A. (2014). Dynamics of Oppression and Coping from Traumatology Perspective: The Example of Palestinian Youth. Peace and Conflict: Journal of Peace Psychology, 20, 385-411. https://doi.org/10.1037/pac0000053

Kira, I., Ashby J. S., Lewandowski, L., Alawneh, A. N., Mohanesh, J., \& Odenat, L. (2013a). Advances in Continuous Traumatic Stress Theory: Traumatogenic Dynamics and Consequences of Intergroup Conflict: The Palestinian Adolescents Case. Psychology, 4, 396-409. https://doi.org/10.4236/psych.2013.44057

Kira, I., Fawzi, M., \& Fawzi, M. (2013b). The Dynamics of Cumulative Trauma and Trauma Types in Adults Patients with Psychiatric Disorders: Two Cross-Cultural Studies. Traumatology: An International Journal, 19, 179-195.

Kira, I., Shuwiekh, H., Al-Huwailah, A., Lewandowski, L., Alawneh, A., Abou-Mediene, S., Al Ibraheem, B., \& Aljakoub, J. (2018). The Central Role of Social Identity in Oppression, Discrimination, and Social-Structural Violence: Collective Identity Traumas, Their Dynamics, and Mental Health Impact: A Brief Report. Peace and Conflict: Journal of Peace Psychology.

Kira, I., Templin, T., Lewandowski, L., Ashby, J. S., Oladele, A., \& Odenat, L. (2012a). Cumulative Trauma Disorder Scale: Two Studies. Psychology, 3, 643-656. 
https://doi.org/10.4236/psych.2012.39099

Kira, I., Templin, T., Lewandowski, L., Ramaswamy, V., Bulent, O., Mohanesh, J., \& Abdulkhaleq, H. (2012b). Collective and Personal Annihilation Anxiety: Measuring Annihilation Anxiety AA. Psychology, 3, 90-99. https://doi.org/10.4236/psych.2012.31015

Krug, G., \& Eberl, A. (2018). What Explains the Negative Effect of Unemployment on Health? An Analysis Accounting for Reverse Causality. Research in Social Stratification and Mobility, 55, 25-39. https://doi.org/10.1016/j.rssm.2018.03.001

Lambert, N. M., Stillman, T. F., Hicks, J. A., Kamble, S., Baumeister, R. F., \& Fincham, F. D. (2013). To Belong Is to Matter: Sense of Belonging Enhances Meaning in Life. Personality and Social Psychology Bulletin, 39, 1418-1427.

https://doi.org/10.1177/0146167213499186

Larsen, S. E., Fleming, C. J. E., \& Resick, P. A. (2018). Residual Symptoms Following Empirically Supported Treatment for PTSD. Psychological Trauma: Theory, Research, Practice, and Policy. https://doi.org/10.1037/tra0000384

LeDoux, J. E., \& Pine, D. S. (2016). Using Neuroscience to Help Understand Fear and Anxiety: A Two-System Framework. American Journal of Psychiatry, 173, 1083-1093. https://doi.org/10.1176/appi.ajp.2016.16030353

Maxwell, S. E., \& Cole, D. A. (2007). Bias in Cross-Sectional Analyses of Longitudinal Mediation. Psychological Methods, 12, 23-44. https://doi.org/10.1037/1082-989X.12.1.23

McLaughlin, K. A., \& Lambert, H. K. (2017). Child Trauma Exposure and Psychopathology: Mechanisms of Risk and Resilience. Current Opinion in Psychology, 14, 29-34. https://doi.org/10.1016/j.copsyc.2016.10.004

Meade, A. W., Johnson, E. C., \& Braddy, P. W. (2008). Power and Sensitivity of Alternative Fit Indices in Tests of Measurement Invariance. Journal of Applied Psychology, 93, 568-592. https://doi.org/10.1037/0021-9010.93.3.568

Pyszczynski, T., Greenberg, J., \& Solomon, S. (1999). A Dual Process Model of Defense against Conscious and Unconscious Death-Related Thoughts: An Extension of Terror Management Theory. Psychological Review, 106, 835-845. https://doi.org/10.1037/0033-295X.106.4.835

Sartre, J. P. (1992). Being and Nothingness: The Principal Text of Modern Existentialism. New York: Washington Square.

Schottenbauer, M. A., Glass, C. R., Arnkoff, D. B., Tendick, V., \& Gray, S. H. (2008). Nonresponse and Dropout Rates in Outcome Studies on PTSD: Review and Methodological Considerations. Psychiatry, 71, 134-168. https://doi.org/10.1521/psyc.2008.71.2.134

Shaver, P. R., \& Mikulincer, M. E. (2012). Meaning, Mortality, and Choice: The Social Psychology of Existential Concerns. American Psychological Association. https://doi.org/10.1037/13748-000

Shrira, A. (2015). Transmitting the Sum of All Fears: Iranian Nuclear Threat Salience among Offspring of Holocaust Survivors. Psychological Trauma: Theory, Research, Practice, and Policy, 7, 364-371. https://doi.org/10.1037/tra0000029

Spinelli, E. (2005). The Interpreted World: An Introduction to Phenomenological Psychology. Thousand Oaks, CA: Sage.

Steenkamp, M. M., Litz, B. T., Hoge, C. W., \& Marmar, C. R. (2015). Psychotherapy for Military-Related PTSD: A Review of Randomized Clinical Trials. JAMA, 314, 489-500. https://doi.org/10.1001/jama.2015.8370

van Bruggen, V., ten Klooster, P., Westerhof, G., Vos, J., de Kleine, E., Bohlmeijer, E., \& Glas, G. (2017). The Existential Concerns Questionnaire (ECQ)-Development and 
Initial Validation of a New Existential Anxiety Scale in a Nonclinical and Clinical Sample. Journal of Clinical Psychology, 73, 1692-1703. https://doi.org/10.1002/jclp.22474

van Bruggen, V., Vos, J., Westerhof, G., Bohlmeijer, E., \& Glas, G. (2015). Systematic Review of Existential Anxiety Instruments. Journal of Humanistic Psychology, 55, 173-201.

Van Pachterbeke, M., Keller, J., \& Saroglou, V. (2012). Flexibility in Existential Beliefs and Worldviews. Journal of Individual Differences, 33, 2-16.

Wanous, J. P., \& Hudy, M. J. (2001). Single-Item Reliability: A Replication and Extension. Organizational Research Methods, 4, 361-375. https://doi.org/10.1177/109442810144003

Weems, C. F., Costa, N. M., Dehon, C., \& Berman, S. L. (2004). Paul Tillich's Theory of Existential Anxiety: A Preliminary Conceptual and Empirical Examination. Anxiety, Stress \& Coping, 17, 383-399. https://doi.org/10.1080/10615800412331318616

Wohl, M. J., Branscombe, N. R., \& Reysen, S. (2010). Perceiving Your Group's Future to Be in Jeopardy: Extinction Threat Induces Collective Angst and the Desire to Strengthen the Ingroup. Personality and Social Psychology Bulletin, 36, 898-910.

Wood, J. V. (1989). Theory and Research Concerning Social Comparisons of Personal Attributes. Psychological Bulletin, 106, 231-248.

https://doi.org/10.1037/0033-2909.106.2.231

Yair, G. (2014). Israeli Existential Anxiety: Cultural Trauma and the Constitution of National Character. Social Identities, 20, 346-362.

https://doi.org/10.1080/13504630.2014.1002390

Yalom, I. D. (1980). Existential Psychotherapy. New York: Basic Books. 


\section{Appendix 1 (See also Kira, Templin, Lewandowski, \& Shuwiekh, 2018)}

\section{Existential Annihilation Anxiety (EAA) Scale (Long Form) (EAA-L)}

Many people have experienced different kinds of events and situations in their lives that challenged their existence personally, or the existence of one of the groups to which they belong. Such challenges may threaten them and made them worry about themselves, their status, their identity or their existence as a person or as a member of the group (for example religious, cultural or ethnic group). These next questions will ask you about some specific or general situations that may or may not have happened to you in the past (during your life) that may let you feel an existential or annihilation threat. Please rate, if you agree or you disagree with each statement according to the scale indicated after each question:

1) Because of what had happened to me personally or is happening to me now, I sometimes worry that I just lose my sense of self (I worry that I will cease to exist as a person).

$\begin{array}{cccc}\text { Strongly Agree } & \text { Agree } & \text { Somewhat Agree } & \text { Disagree } \\ 3 & 2 & 1 & 0\end{array}$

2) The intense violations of me that invaded myself overwhelmed me and made me feel I am losing myself, my independence, fearing of entrapment, or being devoured and losing my ability to function and exist as an autonomous person.

$\begin{array}{cccc}\text { Strongly Agree } & \text { Agree } & \text { Somewhat Agree } & \text { Disagree } \\ 3 & 2 & 1 & 0\end{array}$

3) Because of what had happened to me personally or is happening to me now, being fragmented unable to cope, and of losing control, I fear the disintegration of myself or identity.

$\begin{array}{cccc}\text { Strongly Agree } & \text { Agree } & \text { Somewhat Agree } & \text { Disagree } \\ 3 & 2 & 1 & 0\end{array}$

4) Sometimes I feel the threat of extermination/annihilation/ subjugation (that is, the threat of destruction or "getting rid "of my group ) because of discrimination or stereotyping or acts committed against me, my race, religion, culture, or ethnic or cultural group.

$\begin{array}{cccc}\text { Strongly Agree } & \text { Agree } & \text { Somewhat Agree } & \text { Disagree } \\ 3 & 2 & 1 & 0\end{array}$

5) One of my groups to which I belong had been threatened in the past, or now by annihilation, extermination, or subjugation which made me worry about persecutions and the existence of them and myself.

$\begin{array}{cccc}\text { Strongly Agree } & \text { Agree } & \text { Somewhat Agree } & \text { Disagree } \\ 3 & 2 & 1 & 0\end{array}$

6) Racism, oppression, discrimination, violence and hate against one of my groups to which I belong are humiliating and made me feel that my current 
or future existence threatened.

Strongly Agree Agree

3

2

Somewhat Agree

Disagree

1

0

7) I feel personally threatened by extreme inequalities in this society.

Strongly Agree

3
Agree

2
Somewhat Agree

1
Disagree

8) Belonging to an extremely poor family, or being myself relatively poor, made me worry about my existence and ability to survive.

$\begin{array}{cccc}\text { Strongly Agree } & \text { Agree } & \text { Somewhat Agree } & \text { Disagree } \\ 3 & 2 & 1 & 0\end{array}$

9) Being disadvantaged because of my particularly unequal lower status, makes me feel dissolving, disappearing or losing my value of existence.

$\begin{array}{cccc}\text { Strongly Agree } & \text { Agree } & \text { Somewhat Agree } & \text { Disagree } \\ 3 & 2 & 1 & 0\end{array}$

10) My previous or current loss of job/business made me feel worthless, nothingness, emptiness, fragmented, self-disintegrated and the loss in my ability to function.

$\begin{array}{cccc}\text { Strongly Agree } & \text { Agree } & \text { Somewhat Agree } & \text { Disagree } \\ 3 & 2 & 1 & 0\end{array}$

11) My previous or current failure in school or college made me feel overwhelmed, humiliated, shattered, worthless, nothingness, emptiness, fragmented, self-disintegrated and the loss in my ability to function.

Strongly Agree

3

Agree

2
Somewhat Agree

1
Disagree

0

12) My previous or significant current loss of one of my life assets or achievements, made me overwhelmed, destroyed humiliated, shattered, worthless, nothingness, emptiness, fragmented, self-disintegrated, and caused the loss in my ability to function and fail to exist.

$\begin{array}{cccc}\text { Strongly Agree } & \text { Agree } & \text { Somewhat Agree } & \text { Disagree } \\ 3 & 2 & 1 & 0\end{array}$

13) Because of what had happened or happening to me, I worry about my death (physical elimination).

$\begin{array}{cccc}\text { Strongly Agree } & \text { Agree } & \text { Somewhat Agree } & \text { Disagree } \\ 3 & 2 & 1 & 0\end{array}$

14) Because of what had happened or happening to me, I think a lot about my death.

$\begin{array}{cccc}\text { Strongly Agree } & \text { Agree } & \text { Somewhat Agree } & \text { Disagree } \\ 3 & 2 & 1 & 0\end{array}$

15) Because of what had happened or happening to me, I am very afraid of death. 


$\begin{array}{cccc}\text { Strongly Agree } & \text { Agree } & \text { Somewhat Agree } & \text { Disagree } \\ 3 & 2 & 1 & 0\end{array}$

\section{Scoring Keys}

Items 1-3: Psychic (personal identity) Existential Annihilation Anxiety (EAA) Subscale ( 3 items)

Items 4-7: Collective identity (EAA) Subscale (4 items)

Items 8-12: Status Identity (EAA) Subscale (5 items)

Items 13-15: Physical Identity (EAA) Subscale (3 items)

EAA total scale: 1-15

EAA-S-3 (the old short form): 1, 4, 7

EAA-S-4 (the new short form): items 2, 6, 9, 15

\section{Appendix 2}

\section{Existential Annihilation Anxiety (EAA-S)}

4 items-Short Form

(Use the same instructions as in the Long version)

1) Being disadvantaged because of my particularly unequal or lower status, makes me feel dissolving, disappearing or losing my value of existence. (Single item reliability is 0.76 ).

Strongly Agree

3
Agree

2
Somewhat Agree
Disagree

0

2) Racism, oppression, discrimination, violence and hate against one of my groups to which I belong are humiliating and made me feel that my current or future existence threatened. (Single item reliability is 0.92).

$\begin{array}{cccc}\text { Strongly Agree } & \text { Agree } & \text { Somewhat Agree } & \text { Disagree } \\ 3 & 2 & 1 & 0\end{array}$

3) The serious violations of me that invaded myself overwhelmed me and made me feel I am losing myself, my independence, fearing of entrapment, or being devoured and losing my ability to function and exist as an autonomous person(Single item reliability is 0.78 ).

Strongly Agree

Agree

Somewhat Agree 1

Disagree 0

4) Because of what happened or happening to me, I am terrified of death. (Single item reliability is 0.88 ).

Strongly Agree

3
Agree 2
Somewhat Agree

1
Disagree

0

Note: Each item can be used as single item measure for EAA type. The single reliability of each is established by factor analysis loading (highest loading). According to recommendation for measuring single reliability (Wanous \& Hudy, 2001).

Item 1: Status identity EAA, Item 2: Collective identity EAA, Item 3: Personal (psychic) identity EAA, Item 4: physical identity EAA. 